\title{
Is there a role for the Girdlestone resection arthroplasty in modern orthopedic trauma surgery? Case series from a medically underserved region and literature review
}

\author{
Ngongalah Suhfube Stephane ${ }^{1 *}$, Valentin Neuhaus ${ }^{2}$, Slobodan Mirosavljev ${ }^{3}$ and Bernhard Ciritsis ${ }^{4}$ \\ ${ }^{1}$ Clinica Santa Chiara, Via S. Franscini 4, Locarno, CH, Switzerland \\ ${ }^{2}$ Universitätsspital Zürich Rämistrasse 100, 8091 Zürich, CH, Switzerland \\ ${ }^{3}$ Comité international de la Croix-Rouge,Avenue de la Paix 19, 1202 Genève, CH, Switzerland \\ ${ }^{4}$ Quadrant Orthopedic Center Lungolago Buozzi 25, 28887 Omegna VB, Italy
}

\begin{abstract}
Three cases of proximal femoral fractures due to gunshot wounds were treated with Girdlestone resection arthroplasty. A preoperative functional evaluation and a one year postoperative follow up was performed using the Merle d'Aubigne Score. Despite the unavailability of osteosynthesis or prosthetic implant a good functional result was achieved.

The established surgical procedure of Girdlestone resection arthroplasty represents an effective treatment option for patients with severe fractures of the proximal femur with a high risk of infection, who live in low socio-economic and medically underserved areas. This procedure avoids secondary surgery, chronic infections, fistulas and repeated hospitalization. As a definitive treatment in the geopolitical and surgical setting mentioned, this is a previously undescribed application of the Girdlestone resection arthroplasty.
\end{abstract}

\section{Introduction}

Ballistic fractures of the proximal femur are difficult to treat and require a great deal of surgical expertise and various implants as well as prosthetic options. In 2004 about 234 million major surgical procedures were performed worldwide but only $3.5 \%$ of them in developing countries where the need for alternative simple and lowcomplication treatments with good outcomes is necessary.

In countries belonging to the Organization for Economic Cooperation and Development (OECD), approximately 1.9 million hip prostheses were already implanted in 2011 [1]. Total hip arthroplasty (THA) is considered a very safe operation with low peri- and postoperative complication rates and extremely low mortality. More so, the clinical results show good functional outcomes and pain reduction. Despite these positive outcomes and cost efficiency, the high fixed costs for THA are limiting factors in the implementation of this procedure in developing countries. Furthermore, THA requires good infrastructures consisting of sterilization, material purchasing and organized surgical departments with adequate follow-up treatment. These prerequisites cannot be created on a comprehensive and sustainable basis in lowresource developing countries. Therefore, alternative treatment algorithms for severe hip injuries indicated for prosthetic treatment are necessary.

In this article three complex cases of proximal femoral fractures after gunshot wounds in low-resource and crisis areas are presented.

Because of the clinical conditions and the general setting, Girdlestone resection arthroplasty (GRA) was the chosen therapeutic approach. It provides a safe surgical technique for addressing bone destruction and infections of the proximal femur.

\section{Materials and methods}

\section{Patients' history}

Three cases of patients from a conflict zone (Goma, DR Congo/ November 2014) with destroyed proximal femur as result of a single gunshot wound are reported.

The patients aged 18, 32 and 45 years came with a time lag to the International Committee of the Red Cross (ICRC) led hospital in Goma for treatment. The ICRC is a humanitarian organization providing medical assistance to victims of war and other situations of violence by independently running or supporting hospitals with limited resources [2]. The delay in presentation was multifactorial: infrastructural deficits, safety concerns of the population, lack of information about the available medical care options and economic reasons. Retrospectively it was not possible to determine the exact time lag for each patient, but all cases recorded at least 24 hours delay before first treatment.

In all cases conservative treatment with traction was initiated with preserved peripheral circulation and sensation. There had been no prior surgeries on the injured hip at other external hospitals.

${ }^{\star}$ Correspondence to: Ngongalah Suhfube Stephane, Clinica Santa Chiara, Via S. Franscini 4, Locarno, CH, Switzerland,E-mail: ngongalahs@yahoo.com

Key words: girdlestone, arthroplasty, orthopedic trauma, surgery

Received: December 08, 2020; Accepted: December 15, 2020; Published: December 18, 2020 
Massive functional limitations, pain and complete stiffness were observed in all three cases during the first eight weeks following conservative treatment for the femoral fractures.

The medical history for each patient showed no pre-existing medical conditions. From the leading surgeon's recollection, the basic preoperative blood work showed no signs of significant acute or chronic metabolic disorders.

Initially all patients underwent surgical exploration of the abdomen, debridement and lavage of the shot channels according to the ICRC-Guidelines. A peri- and postoperative antibiotic treatment was initiated according to the ICRC-Guidelines with a triple therapy [3]. During the initial surgery no GRA was performed.

Patient one, 32-year-old male, received a Hartmann procedure for a rectum perforation as part of an emergency laparotomy. He further developed ano-cutaneous fistula, treated conservatively.

Patient two, 45-year-old male received an emergency laparotomy for an intrapelvic gunshot wound due to the intrapelvic shot channel. There were no life-threatening injuries found. The patient was treated with debridement, lavage and primary closure of the abdomen.

Patient three, 18-year-old female suffered a bladder injury, treated with direct suture and catheter insertion after lavage and debridement.

All patients showed complex proximal femoral fractures. Patient two and three also showed an open fracture type Gustillo 3a. Preoperative radiographs showed no signs of bone consolidation in all three patients within a time lapse of eight weeks between trauma and GRA (Figure 1).

Pre-GRA all patients showed closed skin conditions on the injured hip. Furthermore, patient two and three showed no signs of systemic or local infection while patient one had intermittent fever but showed no signs of disseminated infection.

Considering the lack of adequate infrastructure and resources for prosthetic implant or fracture reconstruction, the GRA was deemed adequate and definitive treatment.

Additional decision criteria were the high risk of infection after gunshot wounds, the articular bone defect as well as the fracture pattern with resulting destruction of the vascular supply of the femoral head [4]. There was a written informed consent for surgery in all cases as well as consent for usage of all cases for future publication.

GRA was performed in all patients under general anesthesia without complications. Revision surgery or secondary wound closure

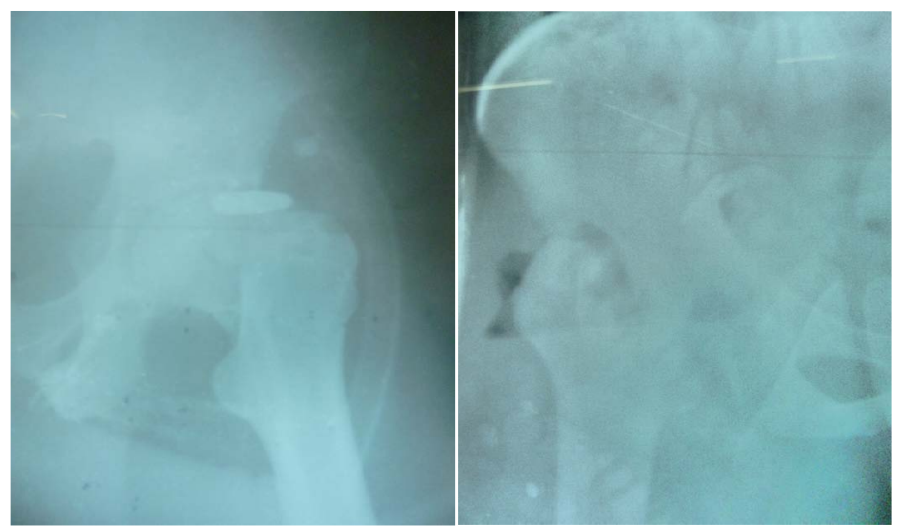

Figure 1. Patient 1, pre- and postoperative x-ray in Patient two and three was not needed. While patient one underwent open wound treatment and secondary surgery closure after five days following ICRC -Guidelines due to infection caused by the intraarticular bullet. After complete wound healing and patient daily mobilization, all patients were discharged. It was retrospectively not possible to evaluate the exact length of stay for each patient. All patients received an adjusted unilateral sole elevation on the operated side three months after GRA. The leg length discrepancy was $3 \mathrm{~cm}$ for patient one and three while $5 \mathrm{~cm}$ in patient two. During outpatient aftercare, the patients continued to receive physiotherapeutic supervision on an irregular basis due to environmental circumstances. The definitive discharge from orthopedic outpatient care was made after one year. GRA.

The initial Merle d'Aubigne Score was documented three days pre-

Clinical follow-ups were performed three and twelve months postoperatively with documentation of the Merle d'Aubigne Score (Table 2).

\section{Surgical technique}

The surgical treatment was performed according to the method developed by Gathorne Robert Girdlestone published in 1943.

The patients were operated in a lateral position. After disinfection and sterile covering, a trans- gluteal approach was performed. The femoral head and neck were then resected. Subsequent visualization and resection of the acetabulum margin, resection of the entire infected and/or destroyed bone and extensive lavage of the surgical area was done. Then layered closure of muscles and fascia fasciae with insertion of a 12 Charier vacuum drainage to enhance granulation of the dead acetabular space.

Postoperative immobilization was performed without external fixation, no weight bearing, and bed rest were applied till complete wound healing.

Subsequently, progressive loading and muscle build-up took place under physiotherapeutic supervision. Explicit postoperative traction treatment was not used in any of the cases.

\section{Scoring system}

The analysis of the functional outcome was performed by pre- and postoperative assessment of the Merle d' Aubigné Score [5]. In detail the 3 parameters used are: pain, range of motion and gait pattern as recorded in Table 2 .

\section{Results (Outcomes)}

Preoperatively, poor values were found in the Merle d'Aubigne score with 2 points for patient one and 3 points for patient two and three. The detailed list and the time course of the scores are shown in Table 1.

In the third month follow-up examination, the Merle d'Aubigne score improved to 12 points for patient one and two, patient three scored 9 points. At this point an adapted insole orthosis fitting was made for all patients to improve the gait pattern. All patients showed proper wound healing without any signs of infection while the mobilization with full weight bearing was achieved. None of the cases requested permanent analgesic or other drugs.

Patient one and two needed one walking-stick most of the time while patient three needed two crutches. 
Stephane NS (2020) Is there a role for the Girdlestone resection arthroplasty in modern orthopedic trauma surgery? Case series from a medically underserved region and literature review

Table 1. Patients characteristics

\begin{tabular}{|c|c|c|c|}
\hline & Patient 1 & Patient 2 & Patient 3 \\
\hline Age in years & 32 & 45 & 18 \\
\hline Sex & Male & Male & Female \\
\hline GSW entry site & Posterior right pelvis & Left iliac wing & Left hip \\
\hline GSW exit site & No & Right tigh & symphysis \\
\hline Preoperative skin condition & Closed & Closed & Closed \\
\hline Preoperative systemic signs of infection & Fever & No & No \\
\hline Preoperative signs of disseminated infection & No & No & No \\
\hline Preoperative WBC & Elevated & Normal & Normal \\
\hline Additional injuries & Rectum perforation & Lesion nerves $\mathrm{S} 1 / 2$ & Bladder perforation \\
\hline Primary surgeries & Hartmann resection & Explorative laparotomy & Bladder repair \\
\hline Merle d’Aubigne score pre OP & 2 & 3 & 3 \\
\hline Merle d'Aubigne score 3 months & 12 & 12 & 9 \\
\hline Merle d'Aubigne score 1 year & 15 & 12 & 13 \\
\hline Leg length discrepancy & $3 \mathrm{~cm}$ & $5 \mathrm{~cm}$ & $3 \mathrm{~cm}$ \\
\hline
\end{tabular}

Table 2. Merle d Aubignie Score

\begin{tabular}{|l|l|l|}
\hline Score (points) & Assesment & Criteria \\
\hline 0 & Intense and permanent & Pain \\
\hline 1 & Severe even at night & \\
\hline 2 & Severe when walking, & \\
\hline 3 & prevents any activity & \\
\hline 4 & Toleable with limited activity & \\
\hline 5 & Mild when walking, disappearing at rest & \\
\hline 6 & Mild and inconsistant; normal activity & Mobility \\
\hline 0 & No pain & \\
\hline 1 & Ankylosis with bad position of hip & \\
\hline 2 & No movement, pain or light deformity & \\
\hline 3 & Flexion $<40^{\circ}$ & \\
\hline 4 & Flexion $40^{\circ}-59^{\circ}$ & \\
\hline 5 & Flexion $60^{\circ}-79^{\circ}$, foot can be reached & \\
\hline 6 & Flexion $80^{\circ}-90^{\circ}$, abduction of at least $15^{\circ}$ & \\
\hline 0 & Flexion exceeds $90^{\circ}$, abduction of $30^{\circ}$ & \\
\hline 1 & None & \\
\hline 2 & Only with crutches & \\
\hline 3 & Only with canes & \\
\hline 4 & With one cane, less than an hour, very difficult & \\
without cane & A long time with a cane, short time without cane & \\
\hline 5 & Normal & \\
\hline 6 & & \\
\hline & & \\
\hline
\end{tabular}

All patients received a third Merle d'Aubigne Score one year postoperatively. The third month results were confirmed or even slightly improved with total scores of 15 points for patient one, 12 points for patient two and 13 points for patient three. This corresponds with a good functional result in all patients. Activities of everyday life could be carried out and independence was restored.

\section{Discussion}

Historically, G. R. Girdlestone published in 1943 his own procedure due to unsatisfactory results with the conventional surgical procedures for pyogenic hip joint infections. The indications were infections caused by haematogenic dissemination and complex fractures after gunshot wounds.

The GRA was the therapy of choice for pyogenic hip joint infections, regardless of the cause of the infection or patient characteristics as it was superior to previously established procedures [6].
A PubMed search with items "girdlestone AND resection arthroplasty AND hip" returned 60 results viewed individually.

Systematic patient records were published as early as 1977. The average age of patients was between 55 and 78 years. Particularly, in the more recent publications an increasing average age of over 60 years was noticeable. The patient cohorts varied in size between 12 and 87 patients. The indications in the literature for GRA were hip joint infections. Especially in more recent publications, infections following THA were the main indication for GRA [7-10].

Nowadays, in industrial societies, improvement in revision arthroplasty and significant advances in conservative and surgical infection treatment made the GRA a salvage procedure in otherwise hopeless situations [11]. These include destroyed joints in uncontrollable infections and polymorbid patients [12-14].

In contrast, individual cases from orthopedically underserved areas showed acceptable to good results according to GRA in younger patients, with just a few or no preexisting conditions [15].

GRA achieved in this case series good functional results with postoperative absence of infection in severe gunshot fractures close to the hip in a medically underserved region. It was a safe, reliable and low-complication surgical procedure that could be performed with low material and personal costs as already described in the literature $[6,7]$. The initial conservative management showed poor results with severely handicapped patients, complete need for care and a high need for analgesics.

The restoration of patients' independence is particularly noteworthy and was also confirmed in the one-year follow-up with an improved Merle d' Aubigne Score.

The achieved functional results through GRA could be seen as an effective means of definitive treatment for fractures near the hip following gunshot wounds in medically underserved areas with lack of prosthetic options.

Analogous results, but in atraumatic hip degeneration could be achieved by GRA in medically similar areas [15]. However, in comparison with the available literature, it must be noted that the functional and esthetic results of the GRA are inferior to prosthetic restoration [8]. With regard to the long-term-outcome there is the possibility of a secondary implantation of THA with better functional results as the technique of revision arthroplasty improves $[9,12]$. 
In this case series context, it must be taken into consideration that neither the medical care situation in the region, the kind of patients nor the indication in developing countries and conflict crisis areas are sufficiently represented in the scientific literature. Thus, a comparison between the outcomes of GRA in the scientific literature with the presented case series is inadequate.

\section{Conclusion}

According to the presented case series and literature review, GRA could represent a valid procedure for the definitive treatment of destructive proximal femoral fractures after gunshot wounds, especially in young, healthy patients and in the absence of medical resources within the framework of orthopedic surgery.

Larger standardized studies on the indication and evaluation of outcomes would be necessary for validation of the GRA.

A discussion of specific treatment strategies and algorithms for these injury patterns in marginal medical care situations is definitely needed.

\section{References}

1. Health at a Glance (2011) OECD Publishing pp: 92-94.

2. Muhrbeck M, Holmgren K, Osman Z, von Schreeb J, Wladis A, et al. (2019) Trends in Demographics and Surgical Treatment of Weapon-Related Limb Injuries Over Two Decades in a Resource-Scarce Setting. World J Surg 43: 2681-2688. [Crossref]

3. Giannou C, Baldan M (2010) War Surgery Working With limited resourcesin armed conflict and other situations of violence volume 1. International Committee of the Red Cross.

4. Zlotorowicz M, Szczodry M, Czubak J, Ciszek B (2011) Anatomy of the medial femoral circumflex artery with respect to the vascularity of the femoral head. $J$ Bone Joint Surg Br 93: 1471-1474. [Crossref]
5. Ugino FK, Righetti CM, Alves DP, Guimarães RP, Honda EK, et al. (2012) Evaluation of the reliability of the modified Merle d'Aubigne and Postel Method. Acta Ortop Bras 20: 213-217. [Crossref]

6. Girdlestone GR (2008) Acute pyogenic arthritis of the hip: an operation giving free access and effective drainage. 1943. Clin Orthop Relat Res 466: 258-263. [Crossref]

7. Basu I, Howes M, Jowett C, Levack B (2011) Girdlestones excision arthroplasty: current update. Int J Surg 9: 310-313. [Crossref]

8. Rittmeister M, Manthei L, Müller M, Hailer NP (2004) Reimplantation of the artificial hip joint in girdlestone hips is superior to girdlestone arthroplasty by itself. $Z$ Orthop Ihre Grenzgeb 142: 559-63. [Crossref]

9. Yamamoto PA, Lahoz GL, Takata ET, Masiero D, Chamlian TR (2007) Evaluation of the function and quality of life of patients submitted to girdlestone's resection arthroplasty. Acta Ortop Bras 15: 214-217

10. Vincenten CM, Den Oudsten BL, Bos PK, Bolder SB, Gosens T (2019) Quality of life and health status after Girdlestone resection arthroplasty in patients with an infected total hip prosthesis. J Bone Jt Infect 4: 10-15. [Crossref]

11. Charlton WP, Hozack WJ, Teloken MA, Rao R, Bissett GA, et al. (2003) Complications associated with reimplantation after girdlestone arthroplasty. Clin Orthop Relat Res 407: 119-126. [Crossref]

12. Li W, Fang X, Zhang C, Xu Y, Huang Z, et al. (2019) Comparison of efficacy and complications between two types of staging arthroplasty in treating chronic septic hip arthritis: A retrospective clinical study. Exp Ther Med 17: 4123-4131. [Crossref]

13. Oheim R, Gille J, Schoop R, Mägerlein S, Grimme CH, et al. (2012) Surgical therapy of hip-joint empyema. Is the Girdlestone arthroplasty still up to date? Int Orthop 36: 927-933. [Crossref]

14. Sharma H, De Leeuw J, Rowley DI (2005) Girdlestone resection arthroplasty following failed surgical procedures. Int Orthop 29: 92-95. [Crossref]

15. Sawadogo M, Kafando H, Ouedraogo S, Korsaga AS, Ouedraogo S, et al. (2018) Is Head and Neck Resection of the Femur (Girdlestone's Procedure) Still Relevant? Indications and Results About 24 Cases. Open Orthop J 12: 69-74. [Crossref]

Copyright: (C2020 Stephane NS. This is an open-access article distributed under the terms of the Creative Commons Attribution License, which permits unrestricted use, distribution, and reproduction in any medium, provided the original author and source are credited. 